\title{
Inibição do desenvolvimento de fungos fitopatogênicos por detergente derivado de óleo da mamona (Ricinus communis)
}

\author{
The castor oil plant detergent (Ricinus communis) inhibits the asexual development of phytopathogenic \\ fungi
}

\section{Eunice Hitomi TakanoI ${ }^{I}$ Cleverson Busso ${ }^{I}$ Evelyn Almeida Lucas Gonçalves ${ }^{\mathrm{I}}$ Gilberto Orivaldo Chierice ${ }^{\mathrm{II}}$ Sérgio Augusto Catanzaro-Guimarães ${ }^{\mathrm{III}}$ Marialba Avezum Alves de Castro-Prado ${ }^{\text {I* }}$}

\section{RESUMO}

No presente estudo avaliou-se o efeito fungitóxico do detergente derivado do óleo da mamona (Ricinus communis) sobre o desenvolvimento dos fitopatógenos: Pyricularia grisea, Fusarium graminearum e Colletotrichum lindemuthianum. Seis concentrações do detergente $(12,5 \mathrm{~mL}$ $L^{-1}$ a $300 \mathrm{~mL} \mathrm{~L}^{-1}$ ) foram, individualmente, incorporadas ao Meio Basal; a seguir, após inoculação fúngica, o crescimento radial dos micélios foi avaliado. A inibição total do desenvolvimento de C. lindemuthianum e P. grisea foi observada entre as concentrações de $50 \mathrm{~mL} \mathrm{~L} \mathrm{~L}^{-1}$ e $200 \mathrm{~mL} \mathrm{~L}^{-1}$, respectivamente. Com base no crescimento miceliano das colônias de $\boldsymbol{F}$. graminearum, a atividade antifúngica do detergente do óleo da mamona (DOM) determinou inibição variável entre 79,4 e 91\% para a raça $\mathrm{F} 2$ e entre 80,7 e $90,7 \%$ para a raça $\mathrm{F} 4$. O detergente, nas concentrações de 100 a 300mL L-1, inibiu em $100 \%$ a germinação de conídios de $\boldsymbol{F}$. graminearum (raças F-4 e F-2). Os resultados demonstram nítida atividade antifúngica do detergente derivado do óleo da mamona sobre fitopatógenos.

Palavras chave: atividade antifúngica, fungos, óleo da mamona, detergentes.

\section{ABSTRACT}

In the present study the fungitoxic effect of the castor oil plant detergent (Ricinus communis) on the development of the phytopathogens Pyricularia grisea, Fusarium graminearum and Colletotrichum lindemuthianum was evaluated. Six concentrations of the detergent $\left(12.5 \mathrm{~mL} \mathrm{~L} \mathrm{~L}^{-1}\right.$ to $300 \mathrm{~mL} \mathrm{~L}^{-1}$ ) had been, individually, incorporated to the Basal Medium. After fungi inoculations, the radial growth of mycelia were evaluated. Detergent at $50 \mathrm{~mL} \mathrm{~L}^{-1}$ and $200 \mathrm{~mL} \mathrm{~L}^{-1}$ inhibited completely the development of P. grisea and C. lindemuthianum, respectively. On the basis of the mycelial growth of $F$. graminearum, the fungitoxic activity of the castor oil plant detergent (DOM) determined inhibition in the range of 79.4 and $91 \%$ for the F2 race and 80.7 and $90.7 \%$ for the F4 race. Detergent at the concentrations of $100 \mathrm{~mL} \mathrm{~L}^{-1}$ to $300 \mathrm{~mL} \mathrm{~L} \mathrm{~L}^{-1}$ inhibited in $100 \%$ the $\boldsymbol{F}$. graminearum germination conidia (races F-4 and F-2). Results demonstrate the fungitoxic activity of the castor oil plant detergent on phytopathogenic fungi.

Key Words: fungitoxic activity, fungus, castor oil, detergent.

\section{INTRODUÇÃO}

A mamoneira (Ricinus communis) é uma planta de origem tropical, resistente à seca e exigente em calor e luminosidade. É considerada uma oleaginosa de alto valor econômico em razão de suas inúmeras possibilidades de aplicação na área industrial. $\mathrm{O}$ fruto da mamoneira apresenta aproveitamento integral, obtendo-se como produto principal o óleo, estável sob variadas condições de pressão e temperatura, e como subproduto a torta, a qual pode ser utilizada como adubo orgânico (COSTA et al., 2004).

O ácido ricinoleico é o principal componente do óleo da mamona, sendo inúmeras as suas aplicações. Além de purgativo, o óleo de rícino pode ser utilizado na fabricação de tintas, corantes, anilinas, desinfetantes, germicidas, óleos lubrificantes de baixa temperatura, colas e aderentes, náilon e matéria plástica. O óleo pode ainda ser utilizado na produção de biodiesel e como base na manufatura de cosméticos e

IDepartamento de Biologia Celular e Genética, Universidade Estadual de Maringá. Av. Colombo, 5790, 87020-900, Maringá, PR, Brasil. *Autor para correspondência.

IInstituto de Química, Universidade de São Carlos, Universidade de São Paulo, CP 369, 13650, São Carlos, SP, Brasil

IIIUniversidade Sagrado Coração de Jesus. Rua Irmã Arminda, 10-50, 17011-160, Bauru, SP, Brasil. 
de muitas drogas farmacêuticas (DE OLIVEIRA et al., 2005; COSTA et al., 2004).

Embora a toxicidade da mamoneira seja conhecida desde tempos remotos, o óleo de rícino não é tóxico, visto que a ricina, proteína tóxica presente nas sementes, não é solúvel em lipídeos, ficando todo o componente tóxico restrito à torta (GAILLARD \& PEPIN, 1999). A ricina inativa específica e irreversivelmente os ribossomos eucarióticos, impedindo a síntese protéica (LORD et al., 1994).

O óleo da mamona, obtido por prensagem das sementes, constitui a substância precursora de um polímero e de uma solução composta por ésteres do ácido ricinoleico, denominada detergente do óleo da mamona (FERREIRA et al., 1999). Implantes de resina de mamona têm se mostrado compatíveis no interior de ossos longos em coelhos (IGNÁCIO et al., 1997), em ossos de cão em fase de crescimento (MARIA et al., 2004) e no reparo de osso alveolar de ratos (CALIXTO et al., 2001). O detergente derivado do óleo da mamona, por sua vez, apresentou propriedade antimicrobiana no tratamento de dentes com necrose de polpa e a atividade bactericida desta substância foi semelhante à do hipoclorito de sódio (FERREIRA et al., 1999; 2002).

No fungo filamentoso Aspergillus nidulans, o detergente derivado do óleo da mamona induziu alterações morfológicas nas colônias e nos conidióforos, atraso na produção de conídios e aumento nas freqüências de recombinação mitótica na linhagem diplóide UT448//UT196 (SOUZA-JÚNIOR et al., 2004).

Diversas plantas silvestres são conhecidas por suas propriedades medicinais e antimicrobianas e, em função disto, grandes esforços têm sido direcionados na busca de métodos alternativos, seguros e de baixo custo, para o controle de doenças em plantas (SITANSU \& DÉB, 1977; TEWARI \& MANDAKINI, 1991; RICE et al., 1998).

O presente trabalho teve como objetivo investigar o efeito do detergente derivado do óleo da mamona (DOM) sobre a germinação de conídios de Fusarium graminearum e sobre o desenvolvimento miceliano dos fitopatógenos Pyricularia grisea, Colletotrichum lindemuthianum e F. graminearum. As concentrações de DOM que induziram másformações nos conidióforos e atraso na conidiogênese em A. nidulans (SOUZA-JÚNIOR et al., 2004) foram tomadas como referência no presente trabalho.

\section{MATERIAL E MÉTODOS}

As espécies fúngicas avaliadas foram Pyricularia grisea (raça BC5), Fusarium graminearum (raças F-2 e F-4) e Colletotrichum lindemuthianum (raça 64). Os isolados de $\boldsymbol{P}$. grisea e $\boldsymbol{F}$. graminearum foram isolados de espigas de trigo com sinais indicativos de brusone e giberela, respectivamente, e coletadas na região de Palotina, Estado do Paraná. O isolado de $\boldsymbol{C}$. lindemuthianum foi, gentilmente, cedido pela Embrapa Arroz e Feijão (Goiás).

Os meios utilizados foram previamente descritos por CORREL et al. (1987) e CRAWFORD et al. (1986): a) Ágar-Batata-Dextrose - $1000 \mathrm{~mL}$ de $\mathrm{H}_{2} \mathrm{O}$ destilada, $250 \mathrm{~g}$ de batata, $15 \mathrm{~g}$ de glicose e $15 \mathrm{~g}$ de Ágar; b) Meio Basal (MB) $-1000 \mathrm{~mL}$ de $\mathrm{H}_{2} \mathrm{O}$ destilada, $30 \mathrm{~g}$ de sacarose, 1 g de $\mathrm{KH}_{2} \mathrm{PO}_{4}$, 0,5g de $\mathrm{MgSO}_{4} .7 \mathrm{H}_{2} \mathrm{O}$, 0,5g de $\mathrm{KCl}, 10 \mathrm{mg} \mathrm{FeSO} 4.7 \mathrm{H}_{2} \mathrm{O}, 2 \mathrm{~g}$ de $\mathrm{NaNO}_{3}, 15 \mathrm{~g}$ de Ágar e $0,2 \mathrm{ml}$ da solução de elementos-traços ( $95 \mathrm{ml}$ de $\mathrm{H}_{2} \mathrm{O}$ destilada, $5 \mathrm{~g}$ de ácido cítrico, $1 \mathrm{~g}$ de $\mathrm{Fe}\left(\mathrm{NH}_{4}\right)_{2}\left(\mathrm{SO}_{4}\right)_{2} .6$ $\mathrm{H}_{2} \mathrm{O}, 0,25 \mathrm{~g}$ de $\mathrm{CuSO}_{4} .5 \mathrm{H}_{2} \mathrm{O}, 50 \mathrm{mg} \mathrm{MnSO}_{4}$. $\mathrm{H}_{2} \mathrm{O}, 50 \mathrm{mg}$ $\mathrm{H}_{3} \mathrm{BO}_{3}, 50 \mathrm{mg} \mathrm{NaMoO}$. $2 \mathrm{H}_{2} \mathrm{O}$ ).

O detergente, gentilmente cedido pelo Prof. Dr. Gilberto Orivaldo Chierice (Instituto de Química de São Carlos, Universidade de São Paulo), foi utilizado no presente trabalho, após esterilização em autoclave, nas concentrações de $12,5 \mathrm{~mL} \mathrm{~L}^{-1}$ a $300 \mathrm{~mL} \mathrm{~L}^{-1}$.

Efeito de DOM sobre o crescimento miceliano (RIBEIRO \& BEDENDO, 1999) - Discos de micélio de $5 \mathrm{~mm}$ de diâmetro, retirados da periferia das colônias de $\boldsymbol{P}$. grisea, $\boldsymbol{C}$. lindemuthianum e $\boldsymbol{F}$. graminearum, cultivadas durante quatro dias em ÁgarBatata-Dextrose a $22 \pm 2^{\circ} \mathrm{C}$, foram inoculados em placas de Petri contendo $\mathrm{MB}+\operatorname{DOM}\left(12,5 \mathrm{~mL} \mathrm{~L}^{-1} \mathrm{a} 300 \mathrm{~mL} \mathrm{~L}^{-1}\right)$. Cada placa corresponde a uma repetição e, para cada tratamento, oito placas foram preparadas. As culturas foram incubadas a $22 \pm 2{ }^{\circ} \mathrm{C}$ em presença e na ausência de luz (12 horas/12 horas). O efeito de DOM sobre o crescimento miceliano dos fitopatógenos foi avaliado através da média do crescimento radial das colônias, o qual foi avaliado em dois eixos ortogonais. As medidas, em milímetros, foram realizadas após 96, 192, 240 e 288 horas de incubação e os resultados obtidos foram estatisticamente comparados utilizando-se o teste de Bonferroni, com 5\% de significância.

O efeito de DOM sobre a germinação de conidios (RIBEIRO \& BEDENDO, 1999; MOLISZEWSKA \& PISAREK, 1996) foi avaliado somente com o patógeno $\boldsymbol{F}$. graminearum devido à menor sensibilidade desta espécie ao detergente. Suspensões de conídios das raças F-2 e F-4 de $\boldsymbol{F}$. graminearum foram, individualmente, preparadas em $\mathrm{NaCl}$ (0,85\%), com conídios coletados de colônias 
cultivadas em Ágar-Batata-Dextrose, após quatro dias de incubação a $22 \pm 2^{\circ} \mathrm{C}$, em presença e em ausência de luz (12 horas/12 horas). Alíquotas de 0,1mL das suspensões de conídios das raças F-2 e F-4, contendo aproximadamente 75 e 94 conídios respectivamente, conforme determinado pela contagem em câmara de Neubauer, foram inoculadas em um total de oito placas de Petri contendo MB, sendo quatro placas para cada raça. As placas foram incubadas por 48 horas a $22 \pm$ $2{ }^{\circ} \mathrm{C}$, em períodos alternados de presença e ausência de luz (12 horas/ 12 horas). A viabilidade dos conídios foi determinada através da fórmula: [ $n^{\circ}$ observado de colônias (NO) $\div\left(n^{\circ}\right.$ esperado de colônias (NE)] x 100 , em que NO é o número observado de colônias formadas nas placas de MB e NE, o número esperado de colônias, sendo NE determinado pela contagem de conídios em câmara de Neubauer.

Para avaliar-se o efeito de DOM sobre a germinação de conídios, alíquotas $(0,1 \mathrm{~mL})$ das suspensões de conídios das raças F-2 e F-4 de $\boldsymbol{F}$. graminearum foram separadamente inoculadas em quatro placas contendo $\mathrm{MB}$ (controle) e quatro contendo MB + DOM $\left(100 \mathrm{~mL} \mathrm{~L}^{-1}, 200 \mathrm{~mL} \mathrm{~L}^{-1} \mathrm{e} 300 \mathrm{~mL} \mathrm{~L}^{-1}\right)$. As placas foram incubadas por 48 horas, conforme descrito acima. Após este período, efetuou-se a contagem das colônias formadas em presença (tratamento) e em ausência de DOM (controle).

\section{RESULTADOS E DISCUSSÃO}

O efeito fungitóxico de DOM sobre o desenvolvimento de $\boldsymbol{P}$. grisea, $\boldsymbol{C}$. lindemuthianum e F. graminearum foi observado em todas as concentrações estudadas (Tabelas 1 a 3). A inibição do crescimento miceliano observada foi diretamente proporcional ao aumento das concentrações de DOM para C. lindemuthianum (raça 64). A inibição total (100\%) do desenvolvimento deste patógeno foi obtida com a dose de $50 \mathrm{~mL} \mathrm{~L}^{-1}$ e, com a dose de $200 \mathrm{~mL} \mathrm{~L}^{-1}$, observou-se também inibição total do isolado BC5 de P. grisea. O efeito inibitório de DOM sobre o crescimento miceliano de $\boldsymbol{P}$. grisea, entretanto, não foi proporcional ao aumento das concentrações utilizadas. Nas menores concentrações, DOM produziu inibições médias de $78,0 \%\left(12,5 \mathrm{~mL} \mathrm{~L}^{-1}\right)$ e $68,3 \%\left(50 \mathrm{~mL} \mathrm{~L}^{-1}\right)$ nas raças 64 (C. lindemuthianum) e BC5 (P. grisea), respectivamente (Tabelas 1 e 2).

F. graminearum foi o patógeno cuja inibição do crescimento colonial requereu as maiores concentrações de DOM, embora as raças F-2 e F-4 tenham respondido igualmente às diferentes concentrações utilizadas $\left(100 \mathrm{~mL} \mathrm{~L}^{-1}\right.$ a $\left.300 \mathrm{~mL} \mathrm{~L}^{-1}\right)$. O efeito antifúngico de DOM produziu valores médios de inibições no crescimento miceliano de $\boldsymbol{F}$. graminearum que variaram de 79,4 a 91,0\% para a raça F-2, e 80,7 a 90,7\% para a raça F-4 (Tabela 3).

A atividade antifúngica de DOM observada no presente estudo é consistente com resultados obtidos em trabalhos anteriores, utilizando-se extratos de sementes e de folhas de $\boldsymbol{R}$. communis (RIBEIRO \& BEDENDO, 1999; KHALLIL, 2001; TEQUIDAMENEZES et al., 2002; HARISH et al., 2004). Em Helminthosporium orizae, extratos aquosos das sementes de $\boldsymbol{R}$. communis inibiram em 55,68\% o crescimento miceliano, sendo que a germinação de conídios do mesmo patógeno foi reduzida em 58,3\% (HARISH et al., 2004).

O efeito fungitóxico de extratos alcoólicos de folhas de $\boldsymbol{R}$. communis foram testados sobre os fungos Aspergillus flavus, Aspergillus niger, Penicillium chrysogenum, Penicillium expansum, Fusarium poae e Fusarium moniliforme. Os extratos metanólicos não inibiram o crescimento de $\boldsymbol{A}$. niger e apresentaram efeito fungicida discreto para os demais fungos testados, com inibição máxima de 48,1\% sobre o crescimento miceliano de A. flavus. Para os extratos

Tabela 1 - Inibição do crescimento miceliano de $\boldsymbol{C}$. lindemuthianum frente ao detergente do óleo da mamona (DOM).

\begin{tabular}{|c|c|c|c|c|c|c|}
\hline \multirow{3}{*}{ Concentrações de DOM (mL L $\left.{ }^{-1}\right)$} & \multicolumn{6}{|c|}{ Período de incubação (dias) } \\
\hline & \multicolumn{2}{|c|}{4} & \multicolumn{2}{|c|}{8} & \multicolumn{2}{|c|}{12} \\
\hline & DMC* & $\mathrm{IC}^{* *}$ & $\mathrm{DMC}^{*}$ & $\mathrm{IC} * *$ & DMC* & $\mathrm{IC}^{* *}$ \\
\hline 0 (Controle) & $16,6 \pm 0,1225$ & - & $31,6 \pm 0,6884$ & - & $46,3 \pm 1,289$ & - \\
\hline 12,5 & $6,5^{\mathrm{a}} \pm 0,4290$ & $61,0^{\mathrm{b}}$ & $8,4^{\mathrm{a}} \pm 0,3446$ & $73,5^{\mathrm{b}}$ & $10,2^{\mathrm{a}} \pm 0,4306$ & $78,0^{\mathrm{b}}$ \\
\hline 25 & $6,0^{\mathrm{a}} \pm 0,0945$ & $64,0^{\mathrm{c}}$ & $7,5^{\mathrm{a}} \pm 0,2588$ & $76,6^{\mathrm{c}}$ & $7,9^{\mathrm{a}} \pm 0,2440$ & $83,0^{c}$ \\
\hline 50 & 0 & $100,0^{\mathrm{d}}$ & 0 & $100,0^{\mathrm{d}}$ & 0 & $100,0^{\mathrm{d}}$ \\
\hline
\end{tabular}

(*) DMC, diâmetro médio das colônias (mm), calculado através da média \pm desvio padrão de oito repetições para cada período de incubação; (**) IC, inibição do crescimento miceliano (\%), calculado pela redução percentual do crescimento médio das colônias em presença de DOM, em relação ao controle (crescimento em ausência de DOM); $\left({ }^{a}\right)$ significativamente diferente do controle, para cada coluna; em cada coluna, os valores não seguidos pela mesma letra diferem entre si pelo teste de Bonferroni, em nível de 5\% de probabilidade de erro. 
Tabela 2 - Inibição do crescimento miceliano de $\boldsymbol{P}$. grisea frente ao detergente do óleo da mamona (DOM).

\begin{tabular}{|c|c|c|c|c|c|c|}
\hline \multirow{3}{*}{ Concentrações de DOM (mL L $\left.{ }^{-1}\right)$} & \multicolumn{6}{|c|}{ Período de incubação (dias) } \\
\hline & \multicolumn{2}{|c|}{4} & \multicolumn{2}{|c|}{8} & \multicolumn{2}{|c|}{12} \\
\hline & $\mathrm{DMC}^{*}$ & $\mathrm{IC}^{* *}$ & DMC* & $\mathrm{IC}^{* *}$ & DMC* & $\mathrm{IC}^{* *}$ \\
\hline 0 (Controle) & $24,8 \pm 0,4472$ & - & $55,6 \pm 1,342$ & - & $70,6 \pm 0,8944$ & - \\
\hline 50 & $9,6^{\mathrm{a}} \pm 0,8944$ & $61,0^{\mathrm{b}}$ & $18,7^{\mathrm{a}} \pm 1,525$ & $66,3^{\mathrm{b}}$ & $22,4^{\mathrm{a}} \pm 1,342$ & $68,3^{\mathrm{b}}$ \\
\hline 100 & 0 & $100,0^{c}$ & $8,8^{\mathrm{a}} \pm 0,2739$ & $84,2^{c}$ & $10,0^{\mathrm{a}} \pm 0,6124$ & $85,8^{\mathrm{c}}$ \\
\hline 200 & 0 & $100,0^{c}$ & 0 & $100,0^{c}$ & 0 & $100,0^{c}$ \\
\hline
\end{tabular}

(*) DMC, diâmetro médio das colônias (mm), calculado através da média \pm desvio padrão de oito repetições para cada período de incubação; (**) IC, inibição do crescimento miceliano (\%), calculado pela redução percentual do crescimento médio das colônias em presença de DOM, em relação ao controle (crescimento em ausência de DOM); ${ }^{a}$ ) significativamente diferente do controle, para cada coluna; em cada coluna, os valores não seguidos pela mesma letra diferem entre si pelo teste de Bonferroni, em nível de 5\% de probabilidade de erro.

etanólicos, foram observados percentuais de inibição que variaram de 5,9\%, para $\boldsymbol{A}$. flavus, a 38,8\% para $\boldsymbol{F}$. poae (TEQUIDA-MENESES et al., 2002).

Extratos aquosos de folhas da mamoneira foram efetivos em inibir a esporulação de $\boldsymbol{C}$. gloeosporioides e a germinação de conídios de Alternaria solani. Em C. gloeosporioides, as inibições variaram de 18,1 a $81,8 \%$, sendo que os maiores percentuais de inibição foram obtidos com as maiores concentrações utilizadas (RIBEIRO \& BEDENDO, 1999). Sobre A. solani, os extratos aquosos de folhas de mamoneira foram capazes de inibir a germinação de conídios em percentuais médios de 84,8×3,0 (KHALLIL, 2001).

No presente trabalho, o efeito de DOM sobre a germinação de conídios foi avaliado nas raças F-2 e F-4 de $\boldsymbol{F}$. graminearum. A viabilidade dos conídios, confirmada após 48 horas de incubação, revelou ser de 70,6\% para F-2 e de 75,7\% para F-4. Concentrações entre $100 \mathrm{~mL} \mathrm{~L}^{-1}$ e $300 \mathrm{~mL} \mathrm{~L}^{-1}$ inibiram completamente a germinação dos conídios dos isolados F-2 e F-4 (Tabela 4). Analisando-se em conjunto os resultados das tabelas 3 e 4, observa-se que, para o patógeno $\boldsymbol{F}$. graminearum, DOM mostrou-se mais efetivo em inibir a germinação de conídios do que o crescimento miceliano do patógeno.

Diversas plantas medicinais foram caracterizadas como fontes naturais de substâncias com potenciais antimicrobianos e fungitóxicos, as quais podem ser utilizadas no controle de fitopatógenos (HARISH et al., 2004; KHALLIL, 2001). A importância de se identificar novos agentes de origem vegetal com efeitos fungitóxicos consiste não somente na eficácia dos extratos, que apresentam efeito inibitório significativo sobre o crescimento de fitopatógenos, como também no efeito inofensivo destes agentes ao homem e ao meio ambiente. Neste sentido, DOM pode vir a constituir uma estratégia alternativa e de baixo custo para o controle de doenças em plantas.

Os resultados do presente estudo indicam o potencial do detergente derivado do óleo da mamona no controle alternativo da antracnose, brusone e giberela por apresentar efeito fungitóxico direto sobre C. lindemuthianum, $P$. grisea e F. graminearum. O

Tabela 3 - Inibição do crescimento miceliano de $\boldsymbol{F}$. graminearum (raças F-2 e F-4) frente ao detergente do óleo da mamona, após quatro dias de incubação.

\begin{tabular}{|c|c|c|c|c|}
\hline \multirow{3}{*}{ Concentrações de DOM (mL L $\left.{ }^{-1}\right)$} & \multicolumn{4}{|c|}{ Raças de $\boldsymbol{F}$. graminearum } \\
\hline & \multicolumn{2}{|c|}{$\mathrm{F}-2$} & \multicolumn{2}{|c|}{ F-4 } \\
\hline & $\mathrm{DMC}^{*}$ & $\mathrm{IC}^{* *}$ & $\mathrm{DMC}^{*}$ & $\mathrm{IC}^{* *}$ \\
\hline 0 (Controle) & $69,5 \pm 2,191$ & - & $64,7 \pm 2,463$ & - \\
\hline 100 & $14,3^{\mathrm{a}} \pm 1,899$ & $79,4^{\mathrm{b}}$ & $12,5^{\mathrm{a}} \pm 1,904$ & $80,7^{\mathrm{b}}$ \\
\hline 200 & $8,6^{a} \pm 2,537$ & $87,6^{\mathrm{c}}$ & $7,6^{\mathrm{a}} \pm 0,8165$ & $88,3^{c}$ \\
\hline 300 & $6,3^{\mathrm{a}} \pm 0,4250$ & $91,0^{\mathrm{c}}$ & $6,1^{\mathrm{a}} \pm 0,8732$ & $90,7^{c}$ \\
\hline
\end{tabular}

(*) DMC, diâmetro médio das colônias (mm), calculado através da média \pm desvio padrão de oito repetições para cada período de incubação; (**) IC, inibição do crescimento miceliano (\%), calculado pela redução percentual do crescimento médio das colônias em presença de DOM, em relação ao controle (crescimento em ausência de DOM); ${ }^{(a)}$ significativamente diferente do controle, para cada coluna; em cada coluna, os valores não seguidos pela mesma letra diferem entre si pelo teste de Bonferroni, em nível de 5\% de probabilidade de erro.

Ciência Rural, v.37, n.5, set-out, 2007. 
Tabela 4 - Efeito do detergente do óleo da mamona (DOM) sobre a germinação de conídios de F. graminearum (raças F-2 e F-4)

\begin{tabular}{|c|c|c|c|c|c|c|}
\hline \multirow[b]{2}{*}{$\begin{array}{l}\text { Concentrações } \\
\text { DOM }\left(\mathrm{mL} \mathrm{L}^{-1}\right)\end{array}$} & \multicolumn{3}{|c|}{$\mathrm{F}-2$} & \multicolumn{3}{|c|}{ F-4 } \\
\hline & $\begin{array}{l}\mathrm{N}^{\mathrm{o}} \text { conídios } \\
\text { inoculados }^{\mathrm{a}}\end{array}$ & $\begin{array}{l}\mathrm{N}^{\mathrm{o}} \text { colônias } \\
\text { formadas }^{\mathrm{b}}\end{array}$ & $\begin{array}{l}\text { Viabilidade dos } \\
\text { conídios (\%) }\end{array}$ & $\begin{array}{l}\mathrm{N}^{\mathrm{o}} \text { conídios } \\
\text { inoculados }^{\mathrm{a}}\end{array}$ & $\begin{array}{l}\mathrm{N}^{\mathrm{o}} \text { colônias } \\
\text { formadas }^{\mathrm{b}}\end{array}$ & $\begin{array}{l}\text { Viabilidade dos } \\
\text { conídios (\%) }\end{array}$ \\
\hline 0 (Controle) & 75 & $53 \pm 0,8165$ & $70.6(53 / 75)$ & 94 & $71 \pm 0,8367$ & $75.7(71 / 94)$ \\
\hline 100 & 75 & 0 & - & 94 & 0 & - \\
\hline 200 & 75 & 0 & - & 94 & 0 & - \\
\hline 300 & 75 & 0 & - & 94 & 0 & - \\
\hline
\end{tabular}

$\left({ }^{a}\right)$ número determinado por contagem de conídios em câmara de Neubauer; $\left({ }^{b}\right)$ média \pm desvio padrão de quatro repetições para cada raça de F. graminearum.

efeito antifúngico de DOM pode ser atribuído a danos causados na parede celular dos microrganismos, com a conseqüente perda de constituintes citoplasmáticos e morte celular. Estudos cromatográficos, para a identificação dos componentes responsáveis pela atividade fungitóxica de DOM, estão sendo realizados.

Embora os resultados obtidos in vitro sejam favoráveis ao emprego de DOM no controle de fungos fitopatogênicos, estudos futuros, desenvolvidos a campo e utilizando diferentes concentrações de DOM, são requeridos para a avaliação da fungitoxicidade do detergente in vivo.

\section{CONCLUSÕES}

O detergente derivado do óleo da mamona (DOM) é um agente potencial para o controle de doenças em plantas, tais como antracnose, brusone e giberela, pois apresenta efeito inibitório sobre o desenvolvimento in vitro dos patógenos $\boldsymbol{C}$. lindemuthianum, $\boldsymbol{P}$. grisea e $\mathbf{F}$. graminearum. DOM inibiu em até $100 \%$ o crescimento miceliano de $\boldsymbol{C}$. lindemuthianum e $\boldsymbol{P}$ grisea. No controle do desenvolvimento de $\boldsymbol{F}$. graminearum, DOM foi mais efetivo em inibir a germinação de conídios do que o crescimento miceliano do patógeno.

\section{REFERÊNCIAS}

CALIXTO, R.F.E. et al. Implante de um floculado de resina de mamona em alvéolo dental de rato. Pesquisa Odontológica Brasileira, v.15, p.257-262, 2001.

CORREL, J.C. et al. Nitrate nonutilizing mutants of Fusarium oxysporum and their use in vegetative compatibility tests. Phytopathology, v.77, p.1640-1646, 1987

COSTA, H.M. et al. Effects from the castor oil on sílica-filled natural rubber compounds. Polímeros, v.14, p.46-50, 2004.
CRAWFORD, M.S. et al. Characterization of the heterokaryotic and vegetative diploid phases of Magnaporthe grisea. Genetics, v.114, p.1111-1129, 1986.

DE OLIVEIRA, D. et al. Optimization of alkaline transesterification of soybean oil and castor oil for biodiesel production. Applied Biochemistry and Biotechnology, v.121, p.553-560, 2005.

FERREIRA, C.M. et al. Evaluation of the antimicrobial activity of three irrigating solutions in teeth with pulpal necrosis. Brazilian Dental Journal, v.10, p.115-121, 1999.

FERREIRA, C.M. et al. Activity of endodontic antibacterial agents against selected anaerobic bacteria. Brazilian Dental Journal, v.13, p.118-122, 2002.

GAILLARD, Y.; PEPIN, G. Poisoning by plant material: review of human cases and analytical determination of main toxins by higher-performance liquid chromatography- (tandem) mass spectrometry. Journal of Chromatography B, v.733, p.181229, 1999

HARISH, S. et al. Mycotoxic effect of seed extracts against Helminthosporium oryzae Breda de Hann, the incitant of rice brown spot. Journal of Biological Sciences, v.4, p.366369, 2004.

IGNÁCIO, H. et al. Uso da poliuretana derivada do óleo da mamona para preencher defeitos ósseos diafisários segmentares do rádio: estudo experimental em coelhos. Revista Brasileira de Ortopedia, v.32, p. 815-821, 1997.

KHALLIL, A-R.M. Phytofungitoxic properties in the aqueous extracts of some plants. Pakistan Journal of Biological Sciences, v.4, p.392-394, 2001.

LORD, M.J. et al. Ricin: structure, mode of action and some current applications. The Faseb Jounal, v.8, p.201-208, 1994.

MARIA, P.P. et al. Poliuretana de mamona para desvio da crista tibial no cão. Ciência Rural, v.34, p.821-827, 2004.

MOLISZEWSKA, E.; PISAREK, I. Influence of humic sibstances on the growth of two phytopathogenic soil fungi. Environment International, v.22, p.579-584, 1996.

RIBEIRO, L.F.; BEDENDO, I.P. Efeito inibitório de extratos vegetais sobre Colletotrichum gleosporioides - agente causal da 
podridão de frutos de mamoeiro. Scientia Agricola, v.56, p.1267-1271, 1999 .

RICE, M.J. et al. Natural products in agriculture: a view from the industry. Pesticides Science, v.51, p.227-234, 1998.

SITANSU, P.; DÉB, G. In vitro bio assay of some plants products against some fungal plant pathogens. Indian Agricola, v.41, p.277-285, 1997.

SOUZA-JÚNIOR, S.A. et al. Loss of heterozygosity by mitotic recombination in diploid strain of Aspergillus nidulans in response to castor oil plant detergent. Brazilian Journal of Biology, v.64, p.885-890, 2004.

TEQUIDA-MENESES, M. et al. Efecto de extractos alcohólicos de plantas silvestres sobre la inhibición de crescimento de Aspergillus flavus, Aspergillus niger, Penicillium chrysogenum, Penicillium expansum, Fusarium moniliforme e Fusarium poae. Revista Iberoamericana de Micologia, v.19, p.84-88, 2002.

TEWARI, S.N., MANDAKINI, N. Activity of four plant leaf extracts against three fungal pathogens of rice. Tropical Agricola, v.68, p.373-375, 1991. 